\title{
Instituições na pecuária de corte e sua influência sobre o avanço da sojicultura na Campanha Gaúcha - Brasil
}

\author{
Institutions in livestock and its influence on the progress of soybeans in the \\ Campanha Gaúcha - Brazil \\ Cinthia Simões da Silva', João Garibaldi Almeida Viana ${ }^{1}$ (1) \\ ${ }^{1}$ Programa de Pós-graduação em Administração, Universidade Federal do Pampa (UNIPAMPA), Santana do Livramento (RS), \\ Brasil. E-mail: ninasimoes2@hotmail.com; joaoviana@unipampa.edu.br
}

Cómo citar: Silva, C. S., \& Viana, J. G. A. (2020). Instituições na pecuária de corte e sua influência sobre o avanço da sojicultura na Campanha Gaúcha - Brasil. Revista de Economia e Sociologia Rural, 58(4), e214991. https://doi.org/10.1590/18069479.2020.214991

Resumo: A produção pecuária é uma atividade de tradição no Rio Grande Sul, caracterizada historicamente por sua exploração em sinergia com os campos naturais do Bioma Pampa. No entanto nas últimas décadas ocorreu forte expansão das lavouras de soja no Pampa brasileiro, determinando mudanças estruturais na atividade e na forma de o pecuarista "pensar". Sob a perspectiva teórica da Economia Institucional, estas mudanças no ambiente social e econômico da atividade pecuária podem ser explicadas pelo comportamento de diversas instituições. Dessa forma, o objetivo do estudo foi analisar as instituições da pecuária de corte e sua influência no avanço da soja na Campanha Gaúcha. A pesquisa teve um caráter descritivo e explicativo, a partir de uma abordagem quantitativa. $O$ método utilizado foi o survey, com a aplicação de um questionário em uma amostra de 95 pecuaristas, sendo 53 "pecuaristas tradicionais" e 42 "pecuaristas sojicultores". A análise dos dados seguiu as técnicas de análise fatorial exploratória, teste de hipótese t-student e regressão Tobit múltipla. Como resultados, foram identificados quatro tipos de instituições na pecuária: Instituições Econômicas, Instituições Organizacionais, Instituições Comportamentais e Instituições Socioambientais. O modelo Tobit demonstrou que o avanço da soja na região é influenciado por motivações de ordem econômica, enquanto instituições informais, como hábitos e padrões de comportamento socioambientais, reprimem o crescimento da cultura agrícola nas propriedades. Como contribuição, o estudo buscou explicar os determinantes institucionais da recente expansão da soja no Pampa Gaúcho, trazendo elementos capazes de induzir políticas de desenvolvimento sustentável e extensão rural nesse território.

Palavras-chave: desenvolvimento rural, economia institucional, economia rural, institucionalismo.

\begin{abstract}
Livestock production is a traditional activity in Rio Grande Sul, historically characterized by its exploitation in synergy with the natural fields of the Pampa Biome. However, in recent decades it has been a strong expansion of soybean crops in the Brazilian Pampas, leading to structural changes in the activity and way of the farmer "think". From the theoretical perspective of Institutional Economics, these changes in the social and economic environment of livestock activity can be explained by the behavior of different institutions. Thus, the aim of this study was to analyze the institutions of livestock and their influence on the advancement of soybean in the Campanha Gaúcha region. The research had a descriptive and explanatory character from a quantitative approach. The method used was the survey, with a questionnaire applied to a sample of 95 farmers, 53 "traditional cattle farmers" and 42 "soy-cattle farmers". Data analysis followed techniques of the exploratory factor analysis, student's t-test and multiple Tobit regression. As a result, four types of livestock institutions were identified: Economic Institutions, Organizational Institutions, Behavioral Institutions and Socio-Environmental Institutions. The Tobit model showed that the advance of soybeans in the region are influenced by economic motivations, while informal institutions, such as social and environmental habits and behavior patterns, repress the growth of agricultural crops on the farmers. As a contribution, this study sought to explain the institutional determinants of the recent expansion of soybean in Pampa Gaúcho, bringing elements capable of inducing policies of sustainable development and rural extension in this territory.
\end{abstract}

Keywords: rural development, Institutional Economics, Agricultural Economics, institutionalism. 


\section{Introdução}

A produção pecuária é uma atividade de grande tradição do Rio Grande Sul. Introduzida no espaço agrário gaúcho por meio dos colonizadores, a bovinocultura foi fundamental no processo de apropriação territorial e na formação de aspectos sociais e econômicos do Estado. Nesse cenário, a produção pecuária no Pampa gaúcho é caracterizada historicamente pela pecuária familiar e pela utilização de um sistema produtivo empresarial tradicional, no qual as práticas e os espaços de criação são adotados por tradição ou herança.

No entanto, nas últimas décadas ocorreram a introdução de novos sistemas de cultivos agrícolas e a diversificação de atividades produtivas nas organizações em busca de maior lucratividade. Desse modo, as áreas tradicionalmente destinadas à produção pecuária deram espaço às lavouras, evidenciando o crescimento das áreas plantadas com grãos, principalmente de soja na metade sul do Rio Grande do Sul (Nicola, 2015; Silveira et al., 2017)

Após os anos 2000, regiões tradicionalmente dedicadas à atividade da bovinocultura de corte e ovinocultura destinaram parte de sua área para a produção de soja, ocasionando mudanças estruturais no cenário da pecuária do Rio Grande do Sul e do Bioma Pampa (Fundação de Economia e Estatística, 2016). A diversificação da atividade agrícola ocorreu de forma mais proeminente em períodos de baixa de preços da bovinocultura de corte, em que a expansão da agricultura de grãos mostrou-se uma alternativa rentável por estar posicionada na base da política agrícola brasileira, sobretudo pelos estímulos dos preços internacionais e pela expansão da demanda externa.

Pesquisa de Kuplich et al. (2018), a partir de metodologia baseada em imagens de sensoriamento remoto, indicou forte expansão das lavouras de soja no Pampa brasileiro e confirmou a necessidade de manejo adequado e conservação dos campos naturais remanescentes do bioma. De acordo com dados do Instituto Brasileiro de Geografia e Estatística (2019), a área plantada de soja na metade sul do Rio Grande do Sul passou de 178.200 hectares no ano de 2000 para 1.039.801 hectares em 2017, demonstrando uma expansão de 583\% no período. Segundo Silveira et al. (2017), a valorização do preço da soja, a partir dos anos 2000, impulsionou a expansão do cultivo do grão na região do Bioma Pampa, incrementando os sistemas produtivos das organizações rurais e transformando as conhecidas pastagens naturais da região em terras agrícolas. Esse cenário causou uma reestruturação do espaço produtivo local, antes dedicado quase exclusivamente à pecuária de corte, modificando aspectos econômicos, culturais e sociais da região.

Entretanto, essas transformações não se restringem apenas ao âmbito produtivo e envolvem mudanças na forma de o pecuarista "pensar", ou seja, organizar seu negócio, utilizar a terra, optar pela complementariedade produtiva, migrar para outra atividade, ou ainda decidir por resistir - não alterar a sua forma de produzir e valorizar "velhas" práticas e resultados. Ou seja, a mudança na dinâmica produtiva da pecuária de corte na Campanha Gaúcha encontrou resistência em produtores rurais, denominados de "tradicionais", os quais optaram por não inserir o cultivo da soja em seus sistemas produtivos e permanecerem dedicados exclusivamente à atividade da bovinocultura de corte ou ovinocultura. Desse modo, esse dualismo de exploração econômica em um mesmo espaço social agrário expõe uma rica realidade empírica para uma análise a partir do arcabouço teórico da Economia Institucional.

A utilização da Economia Institucional possibilita a análise de fenômenos econômicos em que o passado e as instituições importam. Nesse sentido, o processo econômico é influenciado pela história, pelos hábitos dos indivíduos, tradições, costumes, ações coletivas e pelas regras formais e informais da sociedade, convergindo assim para um conceito de Instituição (Veblen, 1898; Commons, 1931; North, 1990). Para a Economia Institucional, novos cenários e mudanças produtivas e econômicas, como o tema central deste estudo, são moldados por diversas instituições. Nesse contexto, e considerando a inserção da sojicultura na região, busca-se responder: Quais as instituições presentes na nova dinâmica da pecuária de corte e sua relação com o avanço da soja na Campanha Gaúcha? 
Desse modo, baseado nos pressupostos da Economia Institucional, o artigo tem como objetivo analisar as instituições da pecuária de corte e sua influência no avanço da soja na Campanha Gaúcha. Como objetivos específicos, busca-se identificar fatores institucionais a partir do resumo de variáveis de instituições formais e informais; comparar as instituições presentes nas organizações rurais de diferentes sistemas de produção pecuários na Campanha Gaúcha e mensurar a influência de fatores institucionais no avanço da soja em organizações pecuárias nas organizações rurais de Pecuaristas Tradicionais e Pecuaristas Sojicultores.

Assim, a contribuição do estudo reside na análise das instituições da pecuária de corte e seu impacto nas escolhas produtivas e mercadológicas de uma região. Ou seja, o ato de desvendar as instituições condicionantes das decisões produtivas de produtores torna-se fundamental para projetar a sustentabilidade dos mercados alimentares provenientes do Bioma Pampa brasileiro. Especialmente, segundo Oliveira et al. (2017), pelo Pampa ser um dos biomas brasileiros com menor cobertura geográfica em unidades de conservação e a responsabilidade de preservação ambiental recair, majoritariamente, sobre as propriedades rurais pecuárias da região. Para os autores, torna-se urgente neutralizar o impacto potencial da expansão agrícola sobre a biodiversidade do Bioma Pampa, portanto, o estudo torna-se relevante ao explicar os determinantes da recente expansão da soja no Pampa Gaúcho, trazendo elementos institucionais capazes de induzir políticas de desenvolvimento sustentável e extensão rural nesse território.

\section{Economia Institucional}

O termo "Economia Institucional" foi apresentado pela primeira vez por Walton Hamilton, em 1919, no seu manifesto "The Institutional Approach to Economic Theory". Walton Hamilton reconhecia que a teoria econômica deveria ser baseada em uma teoria do comportamento humano, na qual o elemento principal para explicá-la eram as instituições. Assim, o termo instituição começava a ser visto como elemento-chave para a economia e objeto de estudo dos economistas (Hodgson, 2000).

No entanto, o campo de pesquisa institucional tem origem no final do século XIX com os estudos de Veblen (1898), Commons (1931) e Mitchell (1910), determinando a escola do Antigo Institucionalismo. Por sua vez, Coase (1937), Williamson (1985), North (1990) e, mais tarde, Hodgson (1998), Rutherford (2001) e Dugger (1990), retomaram a agenda institucionalista, surgindo assim duas novas correntes teóricas: a Nova Economia Institucional e o Neoinstitucionalismo (ou Institucionalismo Evolucionário). O pensamento institucionalista entende os sistemas econômicos inter-relacionados com a evolução histórica de determinada sociedade. Nessa perspectiva, a firma econômica é um nexus de normas de comportamento, governança e tecnologia. Sendo assim, seu foco principal é a importância das instituições no processo de tomada de decisão, de transformação e de desenvolvimento dos mais variados ambientes econômicos. Assim, a seguir, discutem-se as principais contribuições referentes a cada abordagem.

\subsection{Antigo Institucionalismo}

O Antigo Institucionalismo tem seus fundamentos baseados nos estudos de Veblen (1898) e surgiu para romper com as noções abordadas pela Economia Neoclássica. Enquanto o pensamento neoclássico enfatizava as escolhas individuais, o Antigo Institucionalismo abordou os hábitos coletivos e a sua relação com a tomada de decisão da sociedade. O Antigo Institucionalismo enfatiza a importância das instituições na vida econômica e tenta compreender o seu papel e a sua evolução no ambiente (Hodgson, 2000).

Veblen (1898) iniciou os estudos institucionalistas defendendo uma ciência econômica que caracterizava o processo evolutivo das instituições. Veblen abordava que as necessidades e os desejos, o fim e o objetivo, as vias e os meios, provinham dos hábitos dos indivíduos e eram funções de uma variável institucional de caráter totalmente instável, refutando a ideia neoclássica de um indivíduo visto como um ser imutável. Para o autor, o crescimento e as mudanças ocorridas nas instituições são resultado do comportamento 
individual das pessoas, uma vez que as instituições surgem por meio das experiências dos indivíduos. A origem das instituições, para Veblen (1898), está nos hábitos de pensamento criados pelos antecedentes, hereditários e culturais dos indivíduos, que são compartilhados em uma determinada sociedade. Porém, esses hábitos somente serão vistos como instituições quando forem legitimados pelos indivíduos, transformando-se assim em regras ou normas de comportamento e pensamento seguidas pela sociedade.

Outro autor importante foi Commons (1931), que caracterizou a Economia Institucional como uma síntese da Economia, Política, Direito e Ética. O autor abordou a importância das instituições para a economia, apontando que embora houvesse dificuldade em se obter um significado comum para o termo instituição, essa poderia ser caracterizada como uma ação coletiva sob controle, liberação e expansão de ações individuais. Para ele, as crenças individuais são o que move as instituições, e esse reconhecimento é válido tanto na dependência das instituições sobre os indivíduos, quanto na moldagem das ações individuais pelas instituições. Commons (1931) via a economia como algo comportamental e partilhava a ideia de que a análise do comportamento dos indivíduos é a questão-chave para se entender as transações econômicas. O autor analisa o comportamento dos indivíduos enquanto estes participam das transações de mercado, ou seja, é uma análise do comportamento econômico dos indivíduos. A característica peculiar da vontade humana nas atividades econômicas é a escolha entre alternativas, que podem ser voluntárias ou involuntárias, imposta por outro indivíduo ou por uma ação coletiva.

Mitchell (1910) debatia que a teoria econômica marginalista da época explicava a ação humana em termos hedonistas e a considerava superficial, pois o comportamento humano era visto como algo substancialmente ligado à racionalidade econômica, e não influenciado pelo contexto social. Para o autor, no entanto, o contexto social era importante, pois é através dele que as instituições sociais são manifestadas, moldando o comportamento dos indivíduos em padrões comuns a todos. Mitchell (1910) considerava as instituições como um conjunto de hábitos, principalmente pensamentos, que ganharam a aceitação geral dos indivíduos, orientando, através de regras, a conduta destes. O autor inseriu bases psicológicas nos estudos da ciência econômica, definindo as instituições como hábitos mentais, agindo através de entidades e criando regularidades na atividade econômica.

O Antigo Institucionalismo realizou uma série de contribuições para a economia, sob o ponto de vista da ciência por meio da produção de estudos empíricos sobre os ciclos de negócio, e sobre trabalho e movimentos de preços, por exemplo. Dessa forma, a abordagem contribuiu para uma série de debates na economia, trazendo pressupostos diferentes dos que eram abordados pela teoria neoclássica, como psicologia e economia, comportamento empresarial, entre outros assuntos, que foram essenciais para alinhar o ponto de vista do movimento institucional (Rutherford, 2001).

\subsection{Nova Economia Institucional}

A Nova Economia Institucional (NEI) surgiu com os estudos de Ronald Coase, Oliver Williamson e Douglass North, e concentra seus pressupostos nas operações de análise de custos, direitos de propriedade, economia de custos de transação, contratos e organizações. Diferente do Antigo Institucionalismo, a Nova Economia Institucional não refutava os pressupostos da neoclássica, e muitos dos seus estudos foram utilizados para explicar fatores institucionais tradicionalmente tomados como estabelecidos, como os direitos de propriedade e as estruturas de governança (Rutherford, 2001).

Os estudos da NEl estabeleceram-se fundamentalmente na década de 1980 e enfatizavam a ligação com a microeconomia tradicional, afastando-se das abordagens e contribuições do Antigo Institucionalismo, as quais rejeitavam os elementos do neoclassicismo. O surgimento da NEI ocorreu a partir do artigo "The nature of the firm" de Coase (1937), que introduz a ideia de custos de transação na análise econômica da firma. O autor busca explicar a expansão das firmas através das dificuldades em formar relações mercantis ao empregar o sistema de preços. O pensamento econômico de Coase (1937) tinha como objetivo principal entender o funcionamento do sistema econômico por meio de 
mecanismos de coordenação, a fim de economizar em todos os custos envolvidos nas transações econômicas das firmas.

A existência e o funcionamento das firmas em função das falhas do mercado foram elementos centrais da análise de Coase. O autor questionou os motivos pelos quais uma firma permanecia no mercado, e chegou à conclusão de que ela só continuaria a existir se executasse o papel de coordenação, reduzindo custos por meio de decisões administrativas internas, e não por transações de mercado (Coase, 1937).

Na sua compreensão de custos de transação, Coase (1998) destaca que o bem-estar de uma sociedade depende do fluxo de bens e serviços, e este por sua vez depende da produtividade do sistema econômico. No entanto, essa produtividade depende de uma especialização, que somente ocorrerá com a redução dos custos de transação. Nesse sentido, o autor destaca a importância das instituições nesse processo, enfatizando que o sistema jurídico, o sistema político, o sistema social e a cultura de um país são fatores que regem o desempenho de uma economia sendo, portanto, fundamentais na determinação dos custos de transação.

Oliver Williamson aprofunda o conceito de custos de transação, agregando outras abordagens como a do direito e da administração. O autor define as transações como unidade básica de análise e sustenta que a compreensão da economia dos custos de transação é fundamental para o estudo das organizações. As aplicações desta abordagem exigem que as transações sejam dimensionadas e que estruturas de governança sejam descritas e apropriadas às instituições, a fim de ocorrer a minimização desses custos (Williamson, 1985).

A coordenação está relacionada com a construção que os agentes econômicos realizam com o intuito de reduzir os custos de transação, por meio de mecanismos utilizados para controlar uma situação, chamados de estruturas de governança. Estrutura de governança, para Williamson (1985), é um quadro institucional no qual a integridade de uma transação é decidida. Essa estrutura é determinada pelos pressupostos comportamentais (racionalidade limitada e oportunismo) e pelos atributos das transações (especificidade dos ativos, frequência e incerteza). Assim, para cada transação existe uma estrutura de governança mais econômica, em que mercados, formas híbridas e hierarquias surgem como alternativas. Dessa forma, as instituições de governança são suportadas pelo ambiente institucional e pelos indivíduos, objetivando a redução de custos (Williamson, 2000).

Douglass North também utiliza em seus estudos a ideia de custos de transação e de racionalidade limitada, porém voltados para o desenvolvimento econômico. North (1990) aborda o problema enfrentado pelos agentes econômicos devido à existência das incertezas nas transações, introduzindo o conceito de instituições como facilitador da coordenação econômica e social. O autor pontua que os custos de transação são essenciais para o desempenho econômico de um país, e as instituições são responsáveis por determiná-los e reduzirem os custos de transação e produção. A presença das instituições nas transações garantem que os direitos de propriedade e os acordos sejam cumpridos. O poder regulador das instituições, as questões de direito e o ajuste das políticas do ambiente validam e alteram as transações. Dessa forma, as instituições são vistas como econômica e politicamente adaptáveis às novas oportunidades, o que é fundamental para que a sua eficiência seja prolongada (North, 1994).

Segundo North (1990), as instituições constituem as regras do jogo da sociedade e compreendem regras formais (constituições, leis, direitos de propriedade) e regras informais (sanções, tabus, costumes, tradições e códigos de conduta). Para o autor, o grau de identidade que os individuos criam sobre as normas institucionais depende da fiscalização ao cumprimento dessas regras, que podem ser exercidas por meio de códigos de conduta, sanções ou represálias. As instituições são responsáveis pela redução da incerteza nas trocas, e juntamente com as restrições impostas pela economia são responsáveis por determinar os custos de transação e produção da atividade econômica (North, 1990). Douglass North diferencia-se dos demais autores da NEI por considerar que as instituições fazem parte de um processo histórico, aproximando-se assim dos estudos veblenianos. 


\subsection{Neoinstitucionalismo}

Enquanto a NEI procura aproximar as instituições da teoria neoclássica, o neoinstitucionalismo critica o mainstream econômico e concebe uma teoria econômica evolucionária, em que se investiga a mudança através de uma abordagem histórica, estuda-se o processo social de mudança contínua e considera-se a interação entre tecnologia e instituições (Dugger, 1990). Segundo Conceição (2016), o Neoinstitucionalismo retomou os estudos veblenianos, influenciado pelos pressupostos da biologia evolucionária de Darwin, tendo como principais autores Hodgson (1998), Samuels (1995), Rutherford (1998) e Dugger (1990).

Segundo Hodgson (1998), a ênfase nos fatores institucionais e culturais, a análise econômica interdisciplinar, a visão do indivíduo como sujeito ativo e a utilização do conjunto histórico e comparativo das instituições são pressupostos presentes no neoinstitucionalismo e que englobam a crítica ao mainstream econômico. As instituições para Hodgson (1998) são uma consequência dos processos de pensamento (hábitos) que são compartilhados pelas pessoas em uma determinada sociedade. Dessa forma, as instituições são sistemas duradouros de hábitos socialmente aceitos (instintos, cultura e ação), que restringem o comportamento dos indivíduos até que novos hábitos sejam criados. A capacidade de restrição das instituições sociais se molda e determina a origem das novas percepções e disposições dos indivíduos. Com novos hábitos de pensamento e comportamento, surgem novas preferências, e assim novos hábitos são compartilhados servindo como material característico das instituições, proporcionando-lhes maior durabilidade, poder e autoridade normativa (Hodgson,2000).

Os neoinstitucionalistas consideram a evolução da estrutura social como um processo de seleção natural das instituições. Porém, as instituições não são só o resultado de um processo seletivo e adaptativo que molda os hábitos predominantes dos indivíduos, elas são mecanismos especiais da vida e das relações humanas, portanto, agentes dessa seleção. De modo que as mudanças nas instituições ocasionam uma nova adaptação e evolução do temperamento individual no ambiente em mudança, através da formação de novas instituições (Hodgson, 1998).

Segundo Dugger (1990), a abordagem evolutiva abordada pelo neoinstitucionalismo significa o estudo da mudança através de um processo histórico, social e de mudança contínua. A história de vida econômica do indivíduo é um processo de adaptações de meios e fins que cumulativamente mudam à medida que o processo segue. Assim, a evolução das instituições acontece por meio das condições naturais (instintos), como resultado de um processo causal que não depende da intencionalidade ou da avaliação de um esquema institucional em comparação com outro. A mudança econômica é uma mudança de hábitos de pensamento. Na medida em que as mudanças ocorrem, acontece uma transformação no padrão de vida de uma parte ou da totalidade de uma população, que levará ao desenvolvimento de outros hábitos de pensamento, descartando hábitos e instituições estabelecidos anteriormente (Rutherford, 1998).

Nesse sentido, os neoinstitucionalistas enfatizam o papel da cultura no processo causal. A cultura e os processos culturais têm um papel importante na formação das identidades individuais, das metas, das preferências das mercadorias e dos estilos de vida, e impactam a vida econômica e a mudança institucional. A cultura possui interdependência contínua entre os indivíduos, em que o seu comportamento e escolhas contribuem para o enfraquecimento de elementos culturais já existentes e permitem o desenvolvimento de novos elementos culturais (Samuels, 1995). A abordagem neoinstitucionalista contribuiu para a retomada dos estudos institucionais originais, mostrando que as preocupações evolucionistas veblenianas têm uma relevância para o desenvolvimento da economia atual. Nesse sentido, podem-se destacar como principais perspectivas abordadas: o conceito evolucionário baseado nos conceitos de hábito e instinto individuais; o desenvolvimento de uma teoria de evolução socioeconômica de múltiplos níveis, envolvendo seleções de instituições e indivíduos; e a compreensão do papel das instituições, da cultura e da tecnologia no crescimento e desenvolvimento econômico (Hodgson, 2000). 


\subsection{As Instituições e a Economia Rural}

O estudo sobre instituições, mudanças institucionais e meio rural tem despertado o interesse de pesquisadores no ambiente acadêmico a partir de diferentes contextos empíricos. A abordagem predominante nestes estudos é a NEl, com investigações direcionadas às relações contratuais, regras formais e informais e a economia dos custos de transação.

$\mathrm{Na}$ análise de instituições, política agrícola e desenvolvimento, podem-se destacar as pesquisas de Kherallah \& Kirsten (2010) que expõem as contribuições da NEI para a investigação da política agrícola nos países em desenvolvimento, e de High et al. (2005) em verificar como instituições presentes em comunidades rurais influenciam no desenvolvimento rural. Outra importante área de pesquisa sob a ótica da NEl é a análise do ambiente institucional de setores agroindustriais. Nesta perspectiva, destacam-se os estudos de Oliveira \& Silva (2012), ao analisar como os agricultores familiares da cadeia produtiva do leite comportam-se diante das mudanças no ambiente institucional a partir de novas legislações, e de Glasenapp (2016), ao analisar o papel do ambiente institucional nas transformações produtivas e organizacionais das famílias produtoras de tabaco no Rio Grande do Sul

Por sua vez, problemas empíricos analisados sob a ótica do Antigo Institucionalismo apresentam crescimento na literatura. Os estudos de Olsen \& Morgan (2010), na verificação da importância das instituições informais e normas de comportamento sobre as relações de trabalho do meio rural, e de Agne (2014), ao discutir ações políticas locais e como as famílias interpretam e conduzem suas atividades de produção de alimentos, na forma de hábitos de pensamento, são referências nessa linha de aproximação. E seguindo a abordagem neoinstitucionalista, com forte influência da economia evolucionária, Silva \& Cario (2016) buscam aplicar aspectos da teoria evolucionária- institucionalista na discussão sobre o cenário atual do desenvolvimento rural brasileiro, e Viana \& Waquil (2014) analisam a configuração da ovinocultura no Brasil e Uruguai, sob uma perspectiva evolucionária, ao avaliar a probabilidade de aumento da produção ovina por meio de variáveis institucionais e econômicas.

Percebe-se, portanto, a crescente utilização da contribuição teórica da Economia Institucional nos estudos relacionados às organizações e mercados agrícolas, evidenciando a possibilidade de aplicação desses pressupostos em investigações futuras. Embora todas as correntes institucionalistas apresentem elementos relevantes e abrangentes, para a análise das instituições da pecuária de corte e sua influência sobre o avanço da soja na Campanha Gaúcha foram adotados os seguintes pressupostos: a) Instituições como hábitos de pensamento compartilhados; b) Instituições como regras formais e informais; c) Instituições como resultado de um processo evolutivo que molda os hábitos dos indivíduos.

O primeiro pressuposto está relacionado à abordagem teórica do Antigo Institucionalismo, principalmente ao pensamento de Veblen (1898). Nessa perspectiva, as instituições têm um grau significativo de permanência, mesmo diante das mudanças ocorridas nas condições que lhes deram origem. Desta forma, a noção de instituições como hábitos de pensamentos compartilhados é um instrumento relevante para analisar e explicar as instituições e o processo de transformação de hábitos e comportamentos presentes na pecuária de corte da Campanha Gaúcha. O segundo conceito está relacionado à noção de instituição como regras formais e informais caracterizada no estudo de North (1991). A identificação das instituições como leis, políticas públicas e ações econômicas, e as instituições vistas como ações comportamentais e relações sociais, podem auxiliar na identificação das instituições presentes na pecuária de corte. O último pressuposto que define as instituições como parte de um processo evolutivo que molda os hábitos dos indivíduos está relacionado à abordagem Neoinstitucionalista.

Os Neoinstitucionalistas compreendem as instituições como consequência dos hábitos compartilhados pelos indivíduos de uma determinada sociedade, com forte influência do conceito vebleniano. As instituições, no entanto, passam por um processo de seleção natural no qual as mudanças ocorridas nesse meio geram uma nova adaptação e evolução 
do temperamento individual dos indivíduos, ocasionando a formação de novas instituições. Nesse sentido, o entendimento das instituições como parte de um processo evolutivo de mudanças de hábitos pode auxiliar no entendimento e identificação do objeto de estudo. Assim, destaca-se que a utilização dessas três fontes de instituição se dá pela sua convergência conceitual, ao tratar instituições como hábitos, padrões de comportamento e regras do jogo que evoluem ao longo do tempo.

Assim, a seguir, apresenta-se a Figura 1, que tem como finalidade expor um quadro teórico com os pressupostos institucionais utilizados na investigação. Ainda, apresenta as definições que nortearão a aplicação e a análise dos resultados, a fim de determinar quais são as instituições presentes na nova dinâmica da pecuária de corte da Campanha Gaúcha, a partir do avanço da soja na metade sul do Rio Grande do Sul.

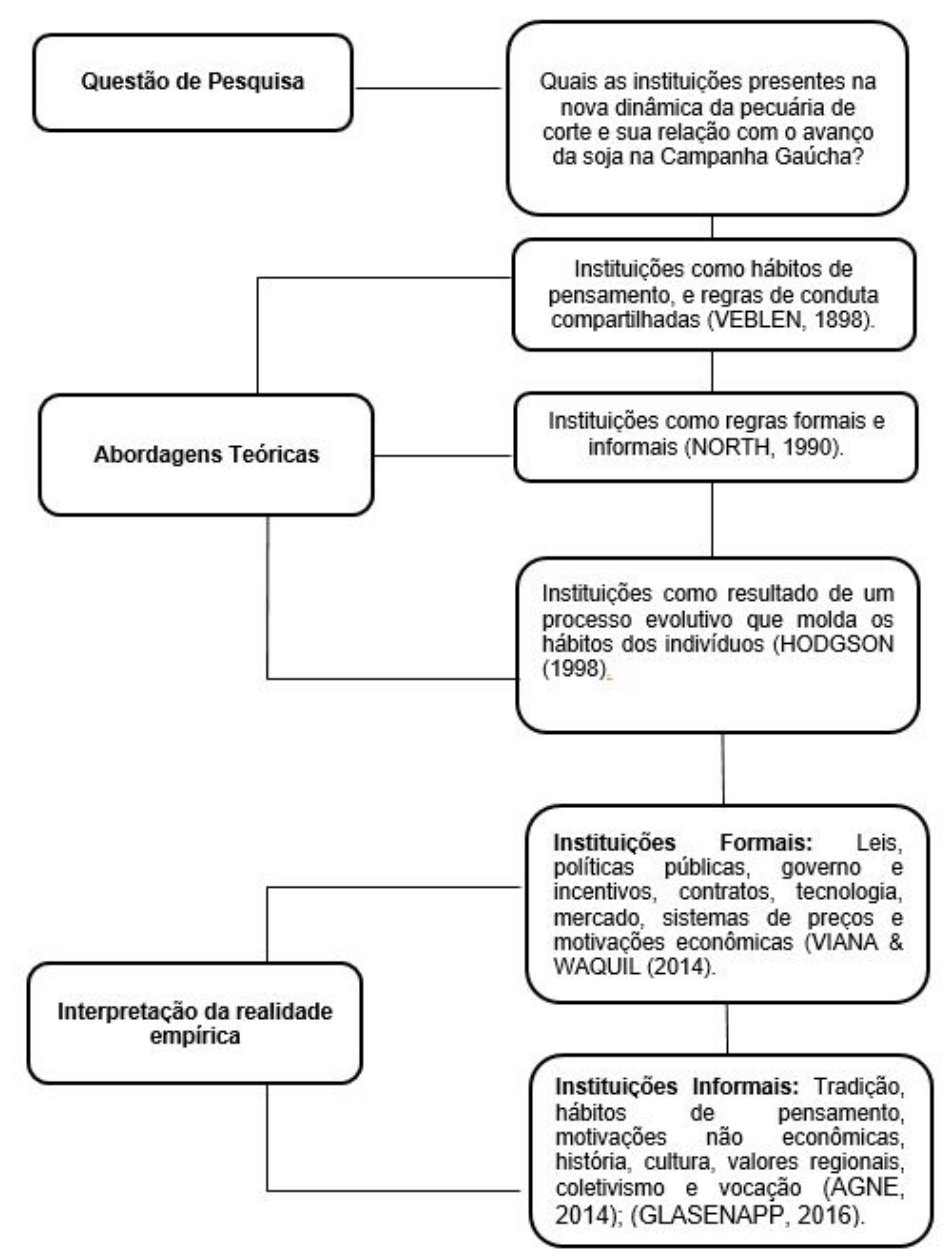

Figura 1: Quadro Teórico da pesquisa

Fonte: Elaborado pelos autores com base no referencial teórico.

\section{Metodologia}

Para verificar as instituições presentes na pecuária de corte da Campanha Gaúcha, buscou-se analisar dois tipos de pecuaristas, sendo eles: a) Pecuaristas Tradicionais produtores que têm como principal atividade a bovinocultura de corte desenvolvida em campo nativo; b) Pecuaristas Sojicultores - produtores que organizam as suas atividades em torno da criação de bovinos de corte e atividades de lavoura de soja.

A amostra foi calculada através do método para variabilidade de uma população (Stevenson, 2001). Os dados utilizados para o cálculo da amostra dos dois grupos corresponderam à produção de soja em toneladas (Pecuaristas Sojicultores) e efetivo de rebanho bovino (Pecuaristas Tradicionais) da mesorregião Sudoeste Rio-grandense no 
período de 2000 a 2015. Os dados foram obtidos junto à Pesquisa Agrícola Municipal e à Pesquisa Pecuária Municipal do Instituto Brasileiro de Geografia e Estatística (Instituto Brasileiro de Geografia e Estatística, 2019). Para o cálculo foi utilizado um nível de confiança de $99 \%$. Assim, o cálculo amostral resultou no total de 95 organizações rurais, sendo 53 de pecuaristas tradicionais e 42 de pecuaristas sojicultores.

A coleta de dados primários partiu da elaboração e organização de um questionário estruturado fundamentado a partir do aporte teórico da abordagem institucionalista e pautado em instrumentos de coleta de dados preexistentes, respaldando-se em autores como Viana \& Waquil (2014), Agne (2014) e Glasenapp (2016).

O questionário buscou caracterizar o perfil produtivo e as características institucionais dos pecuaristas, divididas em Instituições Formais e de Motivação Econômica e Instituições Informais e de Motivações Não Econômicas. As variáveis de características institucionais foram mensuradas em uma escala de importância do tipo likert de cinco pontos $(1=$ sem importância; 2 = pouco importante; 3 = indiferente; 4 = importante; 5 = muito importante). O objetivo da escala foi identificar a presença e a importância de distintas instituições formais e informais no desenvolvimento de suas atividades na organização pecuária. A descrição das variáveis institucionais mensuradas, bem como seu significado, encontra-se na Quadro 1.

Quadro 1 - Descrição e significado das variáveis institucionais da pesquisa.

\begin{tabular}{|c|c|c|}
\hline $\begin{array}{c}\text { Tipo de } \\
\text { Instituição }\end{array}$ & Variável & Significado \\
\hline \multirow{8}{*}{$\begin{array}{l}\text { Instituições } \\
\text { Formais e de } \\
\text { Motivação } \\
\text { Econômica }\end{array}$} & $\begin{array}{l}\text { Busca pela maximização do } \\
\text { lucro }\end{array}$ & $\begin{array}{c}\text { Importância da busca pelo lucro e sua maximização } \\
\text { nas decisões e desenvolvimento das atividades } \\
\text { produtivas. }\end{array}$ \\
\hline & Tecnologia & $\begin{array}{c}\text { Importância da tecnologia e do avanço técnico para } \\
\text { a produção. }\end{array}$ \\
\hline & Acesso a insumos produtivos & $\begin{array}{l}\text { Importância do acesso a insumos destinados ao } \\
\text { manejo nutricional, reprodutivo e sanitário para a } \\
\text { manutenção da atividade pecuária. }\end{array}$ \\
\hline & Informações sobre o mercado & $\begin{array}{l}\text { Importância do uso de informações sobre } \\
\text { comercialização, preços, estoques, etc., para as } \\
\text { decisões produtivas. }\end{array}$ \\
\hline & Sistema legal & $\begin{array}{l}\text { Importância das leis, normas e práticas de } \\
\text { regulação do Estado para o desenvolvimento das } \\
\text { atividades produtivas. }\end{array}$ \\
\hline & Apoio governamental e crédito & $\begin{array}{l}\text { Importância do apoio governamental (municipal, } \\
\text { estadual e federal) e da política de crédito rural } \\
\text { para a atividade pecuária. }\end{array}$ \\
\hline & $\begin{array}{l}\text { Assistência técnica e } \\
\text { institucional }\end{array}$ & $\begin{array}{c}\text { Importância do recebimento de assistência técnica } \\
\text { e do relacionamento com órgãos institucionais, } \\
\text { como universidades, EMBRAPA, etc., nas decisões } \\
\text { produtivas. }\end{array}$ \\
\hline & Coordenação agroindustrial & $\begin{array}{l}\text { Importância de mecanismos de coordenação, como } \\
\text { contratos formais e informais, e da confiança entre } \\
\text { agentes para as transações. }\end{array}$ \\
\hline \multirow{3}{*}{$\begin{array}{c}\text { Instituições } \\
\text { Informais e } \\
\text { de Motivação } \\
\text { Não } \\
\text { Econômica }\end{array}$} & Tradição & $\begin{array}{l}\text { Importância da tradição do produtor na atividade } \\
\text { para o desenvolvimento da pecuária. }\end{array}$ \\
\hline & Satisfação pessoal & $\begin{array}{l}\text { Importância do sentimento de satisfação ao } \\
\text { desenvolver a pecuária para a manutenção e } \\
\text { desenvolvimento futuro da atividade. }\end{array}$ \\
\hline & $\begin{array}{l}\text { História, cultura e valores } \\
\text { regionais }\end{array}$ & $\begin{array}{l}\text { Importância de experiências passadas e de } \\
\text { aspectos e valores culturais no agir dentro da } \\
\text { propriedade. }\end{array}$ \\
\hline
\end{tabular}


Quadro 1 - Continuação...

\begin{tabular}{|c|c|c|}
\hline $\begin{array}{l}\text { Tipo de } \\
\text { Instituição }\end{array}$ & Variável & Significado \\
\hline & Família & $\begin{array}{c}\text { Importância da família nas decisões e no processo } \\
\text { produtivo. }\end{array}$ \\
\hline & $\begin{array}{l}\text { Cooperação e associação com } \\
\text { produtores }\end{array}$ & $\begin{array}{l}\text { Importância da participação em ações coletivas, na } \\
\text { forma cooperada ou associada, para produção e } \\
\text { comercialização. }\end{array}$ \\
\hline & $\begin{array}{c}\text { Busca pela preservação do } \\
\text { Bioma Pampa }\end{array}$ & $\begin{array}{c}\text { Importância da consciência sobre a preservação do } \\
\text { Bioma Pampa para o futuro da pecuária em campo } \\
\text { natural. }\end{array}$ \\
\hline & Busca pela sustentabilidade & $\begin{array}{l}\text { Importância de tomar decisões produtivas sempre } \\
\text { com o foco na sustentabilidade econômica, social e } \\
\text { ambiental da atividade. }\end{array}$ \\
\hline & $\begin{array}{l}\text { Responsabilidade social da } \\
\text { organização rural }\end{array}$ & $\begin{array}{l}\text { Importância da consciência sobre o papel social da } \\
\text { produção pecuária e de sua responsabilidade junto } \\
\text { à sociedade para a tomada de decisão produtiva. }\end{array}$ \\
\hline & Vocação e o "saber fazer" & $\begin{array}{c}\text { Importância da vocação para o trabalho rural e de } \\
\text { práticas oriundas do "saber fazer" para o } \\
\text { desenvolvimento da atividade. }\end{array}$ \\
\hline
\end{tabular}

Fonte: Elaborado pelos autores com base na revisão de literatura.

A pesquisa de campo ocorreu no período de setembro de 2017 a janeiro de 2018. As propriedades rurais foram selecionadas a partir da indicação de associações rurais e profissionais da área. A abrangência geográfica dos selecionados respeitou a representatividade do rebanho bovino de cada município em relação ao total da região da Campanha Gaúcha. Diante disso, foram alcançados estabelecimentos rurais nos munícipios de Aceguá, Alegrete, Bagé, Dom Pedrito, Hulha Negra, Lavras do Sul, Quaraí, Rosário do Sul, Santana do Livramento, São Gabriel e Uruguaiana. Os produtores indicaram sua concordância com o estudo e foi respeitando o anonimato dos produtores rurais em todas as etapas da pesquisa.

Após a medição das variáveis na pesquisa de campo, os dados foram organizados e tabulados. Para identificar os fatores institucionais a partir do resumo de variáveis de instituições formais e informais, das organizações pecuárias da Campanha Gaúcha, foi utilizada a Análise Fatorial Exploratória, técnica que busca analisar inter-relações entre variáveis e explicá-las em termos de fatores comuns (HAIR et al. 2009). Assim, a análise fatorial foi construída com base nas duas seções do questionário relacionadas às questões de Instituições Formais e de Motivações Econômicas, agrupadas em 8 variáveis, e as questões relacionadas às Instituições Informais e de Motivações Não Econômicas, agrupadas em 9 variáveis, totalizando 17 variáveis.

Para a determinação dos fatores da Análise Fatorial, primeiramente foram realizados os testes de adequação da fatorial à amostra de Kaiser-Meyer-Olkin (KMO) e o Teste de Esfericidade de Bartlett. O valor do teste de $\mathrm{KMO}$ pode variar de 0 a 1, e a análise fatorial revela-se apropriada quando os valores forem superiores a 0,50. O Teste de Esfericidade de Bartlett fornece a probabilidade estatística de que a matriz de correlações seja significativa em pelo menos um conjunto de variáveis. Ou seja, um teste de esfericidade de Bartlett significante $(P<0,05)$ indica que existem correlações suficientes entre as variáveis para se proceder uma análise fatorial (Hair, et al., 2009). O modelo de extração de fatores utilizado foi o da Análise de Componentes Principais (ACP). O método de rotação utilizado foi o VARIMAX. Em seguida, identificaram-se as variáveis presentes em cada fator, utilizando-se da observação de cargas fatoriais superiores a 0,50. Além disso, para a verificação da confiabilidade dos fatores, utilizou-se o Alfa de Cronbach, em que os resultados devem apresentar índices maiores ou iguais a 0,6 (Hair et al., 2009).

A fim de comparar as médias dos dois grupos estudados e verificar a existência de diferença ou não nos fatores institucionais presentes na tomada de decisão dos Pecuaristas Tradicionais e Pecuaristas Sojicultores, foi realizado o teste t de Student, com um nível de 
significância máximo de 5\%, tendo como hipóteses: a) $\mathrm{H}_{0}$ : Não existe diferença entre os fatores institucionais dos pecuaristas tradicionais e pecuaristas sojicultores; b) $\mathrm{H}_{1}$ : Existe diferença entre os fatores institucionais dos pecuaristas tradicionais e pecuaristas sojicultores.

Para mensurar a influência de fatores institucionais no avanço da soja em organizações pecuárias da Campanha Gaúcha, estimou-se um modelo de regressão Tobit múltiplo, tendo como variável dependente o percentual de área plantada de soja nas organizações rurais, determinada a partir das respostas dos Pecuaristas Tradicionais e Sojicultores no instrumento de coletas de dados, e como variáveis independentes os fatores institucionais extraídos na Análise Fatorial Exploratória.

Segundo Mcdonald \& Moffitt (1980), o modelo Tobit assume que a variável dependente tem um número de valores agrupados (ou censurados) em um valor limite, geralmente zero. Para os autores, o modelo Tobit pode ser definido como um modelo de variável latente (equação 1):

$$
\begin{array}{rlrl}
\hat{y}_{i}=\beta X_{i}+\varepsilon_{i}, & & \text { se }, \beta X_{i}+\varepsilon_{i}>0 \\
& =0 & & \text { se } \beta X_{i}+\varepsilon_{i} \leq 0 \\
& & i=1,2, \ldots, n .
\end{array}
$$

A variável y observada é igual a $\hat{y}$, quando $\hat{y} \geq 0$, mas $\mathrm{y}=0$ quando o percentual de área plantada de soja é zero para uma parcela significativa da amostra, como no caso em análise. Dessa forma, devido à variável dependente ser censurada à esquerda $(y=0)$, o modelo Tobit é uma alternativa ao método de Mínimos Quadrados Ordinários (MQO) do modelo clássico de regressão linear. Dessa forma, o modelo Tobit aplicado na pesquisa pode ser representado pela equação 2:

$Y_{i}=\alpha+\beta_{1} X_{1 i}+\beta_{2} X_{2 i}+\cdots+\beta_{k} X_{k i}+\varepsilon_{i}$

Onde: $Y_{i}=\%$ área plantada de soja

$a=$ intercepto;

$\beta=$ coeficiente angular;

$X_{i}=$ fatores institucionais;

$\varepsilon_{\mathrm{i}}=$ resíduo

Os parâmetros da regressão Tobit foram estimados pelo Método de Máxima Verossimilhança, por meio do software EViews 10. Segundo Gujarati (2006), os coeficientes do modelo Tobit estimados por máxima verossimilhança podem ser interpretados como quaisquer outros coeficientes de regressão. As hipóteses testadas foram: a) $H_{0}: \beta_{j}=0$; Não há influência da variável independente (fatores institucionais) sobre a variável dependente (\% de área plantada de soja) nas organizações rurais amostradas; b) $\mathrm{H}_{1}: \beta_{\mathrm{j}} \neq 0$ ); Há influência de pelo menos uma variável independente (fatores institucionais) sobre a variável dependente (\% área plantada de soja) nas organizações rurais amostradas.

\section{Resultados e Discussão}

A forma com que os pecuaristas da região da Campanha organizam as suas atividades agropecuárias estão conectadas às suas histórias de vida e a modos de pensar e agir. Nesse contexto, os diferentes modos com que as atividades são desenvolvidas nas organizações rurais pressupõem hábitos de pensamento e comportamento que podem ser manifestados tanto de forma convergente quanto divergente nos diferentes grupos de pecuaristas.

Esses hábitos, chamados de instituições, são formados por Instituições Formais e Motivações Econômicas e Instituições Informais e de Motivações Não Econômicas, e ajudam a interpretar e identificar o modo com que os pecuaristas conduzem as suas atividades, bem como caracterizar o perfil institucional desses pecuaristas. Dessa forma, explorar as diferentes instituições que fazem parte desse cenário é importante para compreender como 
estas interferem na realidade da pecuária de corte da região e no processo de mudança organizacional e institucional.

Para tanto, considerando a diversidade de instituições presentes nessa atividade, fez-se necessário verificar a existência de possíveis semelhanças entre elas, buscando reduzir os dados explorados por meio da Análise Fatorial Exploratória (EFA). Dessa forma, foram realizadas duas análises fatoriais a fim de agrupar variáveis de Instituições Formais e Motivações Econômicas (8 variáveis) e Instituições Informais e Motivações Não Econômicas (9 variáveis).

O primeiro passo realizado foi verificar os resultados dos testes $\mathrm{KMO}$ e de Bartlett utilizados para analisar a adequação da fatorial à amostra. Assim, os resultados foram satisfatórios nos dois conjuntos de variáveis (KMO>0,50 e Bartlett $\mathrm{P}<0,01)$, demonstrando correlações suficientes para o agrupamento. Para chegar aos fatores, utilizou-se a rotação do tipo Varimax com extração pela Análise de Componentes Principais (ACP) e critério de raiz latente, foram considerados significantes os fatores com autovalores maiores do que 1.

A Figura 2 apresenta o diagrama de declividade (Scree Plot) realizado nos dois grupos de componentes. Assim, ao observar os diagramas de declividade, constata-se que os autovalores declinam de forma aproximadamente linear a partir no segundo componente, apresentando a existência de apenas dois fatores com autovalores superiores a 1 nas duas análises de componentes principais realizadas.
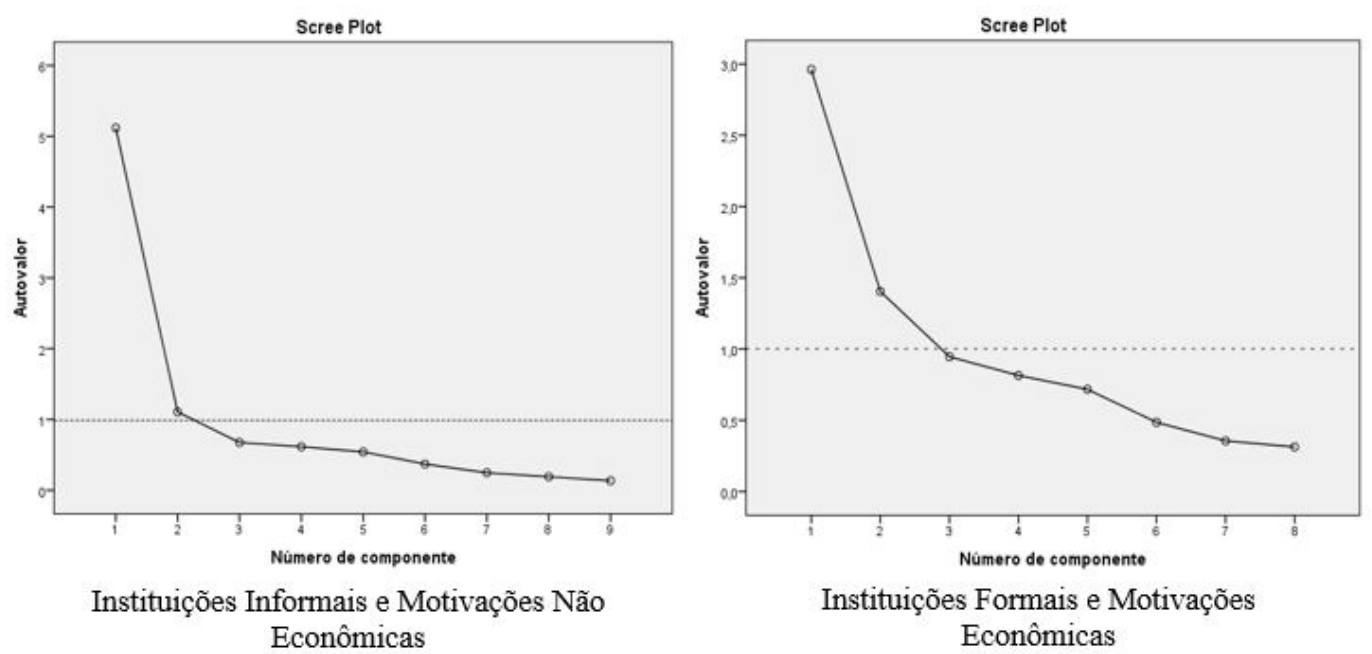

Figura 2 - Estimativas dos autovalores em função do número de fatores (Diagrama de declividade Scree Plot).

Fonte: Elaborado pelos autores com base nos dados da pesquisa.

Dessa forma, observando a extração dos componentes principais das variáveis institucionais formais e motivações econômicas, foi possível identificar que dois componentes apresentaram autovalores maiores que 1. Uma verificação nos autovalores mostra que o primeiro componente principal apresenta um autovalor de 2,96, o que explica $37,03 \%$ da variação. Já o segundo componente apresentou um autovalor de 1,40, o que explica $17,55 \%$ da variação. Assim, esses dois autovalores explicam $54,58 \%$ do total da variância dos dados observados

No que se refere às variáveis Institucionais Informais e Motivações Não Econômicas, foi possível verificar através da ACP que estas variáveis também apresentaram apenas dois componentes com autovalores maiores que 1. O primeiro deles conseguiu captar uma variação dos dados de 5,10, explicando $56,89 \%$ da variação dos dados; o segundo componente apresentou uma variação de dados de 1,10, explicando assim 12,29\% dos dados. Dessa forma, tem-se que juntos os dois componentes representam $69,18 \%$ do total da variância dos componentes. 
Após a análise dos componentes principais, rotacionaram-se os fatores pelo método VARIMAX, a fim de verificar a significância das cargas fatoriais. A composição dos fatores baseou-se na seleção das variáveis que apresentaram cargas superiores ou iguais a 0,50 em cada fator. Desse modo, apresenta-se na Tabela 1 as cargas fatoriais obtidas na ACP de dois fatores de variáveis Institucionais Formais e de Motivações Econômicas. As variáveis "Busca pela maximização de lucro", "Tecnologia", "Acesso a insumos produtivos", "Informações sobre o mercado" apresentaram cargas fatoriais superiores a 0,5, compondo assim o Fator 1. As variáveis "Apoio governamental e linhas de crédito rural", "Assistência técnica e institucional" e "Coordenação agroindustrial" apresentaram cargas fatoriais superiores a 0,5 no Fator 2. Verifica-se que a variável "Sistema legal" apresentou carga fatorial menor que 0,50 nos dois fatores, não fazendo parte de nenhum dos constructos extraídos.

Tabela 1 - Cargas Fatoriais obtidas nas variáveis institucionais Formais e Motivações Econômicas

\begin{tabular}{ccc} 
Variáveis & \multicolumn{2}{c}{ Fatores* } \\
\cline { 2 - 3 } Busca pela maximização de lucro & $\mathbf{1}$ & $\mathbf{2}$ \\
Tecnologia & $\mathbf{0 , 7 6 5}$ & $-0,022$ \\
Acesso a insumos produtivos & $\mathbf{0 , 7 4 7}$ & 0,212 \\
Sistema legal (leis, normas, regulação, etc.) & $\mathbf{0 , 6 9 1}$ & 0,141 \\
Apoio Governamental e Linhas de Crédito Rural & $\mathbf{0 , 6 1 9}$ & 0,120 \\
Assistência técnica e institucional & $\mathbf{0 , 4 1 3}$ & $\mathbf{0 , 3 5 7}$ \\
Coordenação agroindustrial (confiança, contratos, integração, etc.) & $\mathbf{0 , 3 0 1}$ & $\mathbf{0 , 7 2 4}$ \\
\hline Ascostoques) & 0,063 & $\mathbf{0 , 8 3 2}$
\end{tabular}

* As cargas fatoriais em negrito indicam o fator no qual a variável foi alocada.

Fonte: Elaborado pelos autores com base nos dados da pesquisa

Na Tabela 2 apresentam-se as cargas fatoriais obtidas na ACP de dois fatores com variáveis Institucionais Informais e Motivações Não Econômicas. Após a realização da análise fatorial, observou-se que as variáveis "Tradição", "Satisfação pessoal", "História, cultura e valores regionais" e "Família" apresentaram cargas fatoriais superiores a 0,5 no Fator 1. Por sua vez, as variáveis "Cooperação e associação", "Busca pela preservação do Bioma Pampa", "Busca pela sustentabilidade", "Responsabilidade social da empresa" e "Vocação" apresentaram cargas fatoriais superior a 0,5 no Fator 2.

Assim, após a análise de significância das cargas fatoriais e a distinção dos fatores, buscam-se a caracterização e a interpretação dos fatores. Dessa forma, foram identificados, portanto, quatro fatores: Instituições Econômicas, Instituições Organizacionais relacionadas às variáveis institucionais formais e econômicas, e Instituições Comportamentais e Instituições Socioambientais, relacionadas às variáveis institucionais informais e de motivações não econômicas.

A denominação do fator de Instituições Econômicas se deve pela composição de varáveis associadas a questões econômicas e mercadológicas da estrutura produtiva e de decisão dos pecuaristas. A maior carga neste fator foi relacionada à variável que indica a importância da busca pela maximização do lucro, seguida pela importância da tecnologia, acesso a insumos produtivos e informações sobre o mercado no desenvolvimento das atividades agropecuárias. 
Tabela 2 - Cargas Fatoriais obtidas nas variáveis Institucionais Informais e Motivações Não Econômicas

\begin{tabular}{|c|c|c|}
\hline \multirow{2}{*}{ Variáveis } & \multicolumn{2}{|c|}{ Fatores* } \\
\hline & 1 & 2 \\
\hline Tradição & 0,896 & 0,031 \\
\hline Satisfação pessoal & 0,616 & 0,468 \\
\hline História, cultura e valores regionais & 0,860 & 0,220 \\
\hline Família & 0,544 & 0,481 \\
\hline Cooperação e associação com produtores & $-0,091$ & 0,850 \\
\hline Busca pela preservação do Bioma Pampa & 0,602 & 0,615 \\
\hline Busca pela sustentabilidade & 0,552 & 0,698 \\
\hline Responsabilidade social da empresa rural & 0,522 & 0,651 \\
\hline Vocação e o "saber fazer" & 0,323 & 0,666 \\
\hline
\end{tabular}

* As cargas fatoriais em negrito indicam o fator no qual a variável foi alocada.

Fonte: Elaborado pelos autores com base nos dados da pesquisa

O fator Instituições Organizacionais indica a importância da assistência técnica e institucional, como a EMATER, EMBRAPA, Universidades, entre outras, na realização das atividades agropecuárias das organizações rurais. Seguido da coordenação agroindustrial, que indica o relacionamento com indústria na forma de contratos, integração, etc., e apoio governamental e linhas de crédito rural. Assim, observa-se que as variáveis que compõem esses dois fatores se aproximam das instituições caracterizadas como formais apontadas por Williamson (1985) e North (1991) nos estudos da Nova Economia Institucional, pois englobam estruturas de governança e as "regras do jogo" como leis, políticas, ambiente macroeconômico e direitos de propriedade.

Em relação ao fator Instituições Comportamentais, está caracterizado pela importância dos hábitos de pensamento dos indivíduos, especialmente vinculados ao processo de replicação de costumes e comportamentos individuais. Na visão de Veblen (1987), essas instituições são firmadas por meio sanção social e repassadas ao longo do tempo para outros indivíduos de uma sociedade, e têm um grau significativo de permanência, mesmo diante das mudanças ocorridas nas condições que Ihes deram origem.

Já as Instituições Socioambientais podem ser caracterizadas como instituições presentes em hábitos, e valores comuns que motivam as atividades, a vivência e a convivência dos pecuaristas. A preservação do ambiente, a sustentabilidade, a cooperação com produtores e a responsabilidade social da empresa remetem a ações que possibilitam o envolvimento dos pecuaristas com organizações de apoio, e a formação de ações coletivas que envolvem desde costumes individuais a interesses sociais formando os padrões de conduta do grupo, relacionando-se intimamente com o conceito de instituição de Commons (1931).

Portanto, pode-se afirmar que os fatores Instituições Comportamentais e Instituições Socioambientais estão fortemente ligados a hábitos firmados em valores, costumes, códigos de conduta, laços familiares e atitudes de um grupo social, os quais representam um papel importante no comportamento dos agentes e no processo decisório.

Diante da compreensão de tais fatores (Figura 3), evidencia-se que a presença de diferentes motivações e características institucionais dos indivíduos influenciam a forma com que pensam e agem. Nesse sentido, é possível questionar, por exemplo, se a motivação que influenciou um pecuarista a modificar seus hábitos de pensamento e comportamento ao inserir o cultivo de soja nas suas organizações rurais é diferente das motivações que influenciaram o Pecuarista Tradicional a resistir e não inserir o cultivo de soja em suas organizações. 


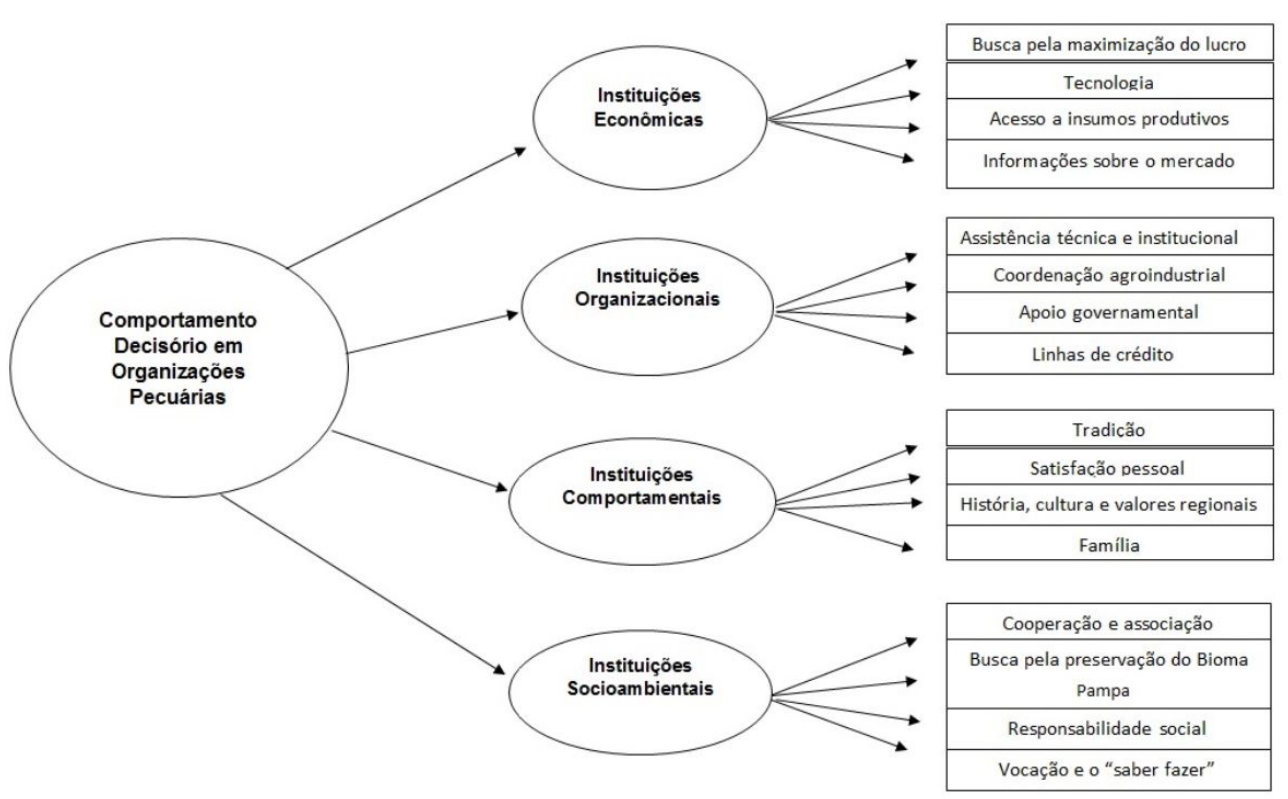

Figura 3 - Composição do comportamento decisório das organizações pecuárias da Campanha Gaúcha a partir de fatores institucionais extraídos na pesquisa.

Fonte: Elaborado pelos autores com base nos dados da pesquisa

Para verificar essas possíveis diferenças, torna-se necessário comparar as instituições presentes nas organizações rurais de diferentes sistemas de produção pecuários na Campanha Gaúcha. Para tanto, utilizou-se o teste de hipótese t-student para amostras independentes, em que foram considerados os fatores institucionais selecionados pelo estudo (Tabela 3).

Tabela 3 - Testes de hipóteses dos fatores institucionais do estudo

\begin{tabular}{|c|c|c|c|c|}
\hline \multirow{2}{*}{ Fatores } & $\begin{array}{l}\text { Pecuaristas } \\
\text { Tradicionais }\end{array}$ & $\begin{array}{l}\text { Pecuaristas } \\
\text { Sojicultores }\end{array}$ & \multirow{2}{*}{$\mathbf{t}$} & \multirow{2}{*}{ Valor $p$} \\
\hline & Média & Média & & \\
\hline Instituições Comportamentais* & 4,09 & 3,36 & 3,80 & 0,00 \\
\hline Instituições Socioambientais* & 4,12 & 3,43 & 3,91 & 0,00 \\
\hline Instituições Econômicas & 4,21 & 4,31 & $-0,82$ & 0,41 \\
\hline Instituições Organizacionais & 3,72 & 3,93 & $-1,27$ & 0,21 \\
\hline
\end{tabular}

$*(P<0,01)$.

Fonte: Elaborado pelos autores com base nos dados da pesquisa

É relevante destacar que a amostra de Pecuaristas Tradicionais apresenta uma média superior nos fatores Comportamentais e Socioambientais $(P<0,01)$. Isto é, o Pecuarista Tradicional determina mais importância às instituições informais no desenvolvimento de suas atividades dentro das organizações rurais. Percebe-se que a trajetória destas organizações é marcada pelo ambiente institucional oriundo do passado, fato que converge com o conceito de Path dependence de North (1991), em que permanecem alicerçados nas memórias e traços socioculturais que percorrem as gerações destas organizações. Pode-se dizer que o ambiente institucional é constituído pelas regras informais, como a cultura, tradição e trajetória histórica do grupo, influenciando de tal modo a tomada de decisão das organizações, as transformações produtivas e organizacionais, e determinando o comportamento dos Pecuaristas Tradicionais. 
Cabe destacar que a presença de instituições informais, aqui resumidas em Instituições Comportamentais e Socioambientais, pode estar relacionada à resistência dos Pecuaristas Tradicionais em inserir o cultivo de soja nas suas organizações rurais. Desse modo, a presença dessas instituições inviabiliza a substituição da atividade pecuária por razões unicamente econômica, balizadas na otimização da alocação de recursos e maximização via sistema de preços por exemplo.

Os Pecuaristas Sojicultores, por sua vez, apesar de não apresentar diferença significativa, obtiveram médias absolutas superiores nos fatores Econômicos e Organizacionais, demonstrando maior aproximação com as instituições relacionadas ao lucro e à coordenação das atividades agropecuárias. Dessa forma, observa-se que as transformações produtivas e organizacionais e a tomada de decisão dos Pecuaristas Sojicultores podem estar mais fortemente alicerçadas em aspectos formais demonstrados pelo ambiente institucional que permeiam estas organizações, ou seja, pelas regras do jogo como o sistema de preços, a política, as leis de contratos e propriedade (Williamson, 2000).

Os resultados até aqui obtidos demonstram diferenças significativas entre as variáveis institucionais caracterizadas nos perfis de pecuaristas estudados, demonstrando que, enquanto os Pecuaristas Tradicionais demonstram um caráter de enraizamento de características influenciadas pelo padrão histórico e satisfação pessoal na realização da atividade pecuárias, os Pecuaristas Sojicultores são mais influenciados pelas características e motivações econômicas para o desenvolvimento de suas atividades.

A fim de verificar a influência dessas variáveis institucionais no avanço da soja em organizações pecuárias da Campanha Gaúcha, estimou-se um modelo de regressão Tobit múltiplo, sendo a variável dependente o percentual de área plantada de soja na propriedade, e as variáveis independentes os fatores institucionais construídos pela Análise Fatorial - Instituições Comportamentais, Socioambientais, Econômicas e Organizacionais. Os resultados da regressão são apresentados na Tabela 4.

Tabela 4 - Parâmetros do modelo de regressão múltipla da relação entre percentual de área de soja e fatores institucionais.

\begin{tabular}{ccccc} 
Modelo & Coeficientes & Erro Padrão & Estatística Z & Valor $\mathbf{p}$ \\
Constante & 65,113 & 23,490 & 2,771 & 0,005 \\
Instituições Comportamentais & $-7,030$ & 3,874 & $-1,814$ & 0,069 \\
Instituições Socioambientais & $-15,167$ & 3,880 & $-3,908$ & 0,000 \\
Instituições Econômicas & 8,908 & 4,622 & 1,927 & 0,054 \\
Instituições Organizacionais & 0,884 & 3,071 & 0,288 & 0,773 \\
\hline
\end{tabular}

Fonte: Elaborado pelo autor com base nos dados da pesquisa

Evidencia-se a existência de uma relação de dependência entre Instituições Socioambientais e o percentual de cultivo de soja nas organizações pecuárias amostradas, com um nível de significância de 1\%. A análise do coeficiente angular desse fator indica que a cada elevação de um ponto na escala de importância do fator "instituição socioambiental" ocorre uma redução de 15,16\% na área plantada com soja nas organizações pecuárias, mantendo os demais fatores constantes. Dessa maneira, quanto maior a busca pela preservação do Bioma Pampa, traduzido no fortalecimento de instituições como a busca pela sustentabilidade, a cooperação, o saber fazer e a responsabilidade social da organização rural, menor será o avanço do cultivo de soja nestas organizações da região da Campanha Gaúcha.

Considerando ainda um nível de significância de 10\%, constata-se que as Instituições Comportamentais influenciam negativamente a área plantada de soja na região da Campanha. Nos resultados, verifica-se que para cada aumento na escala de importância do fator "Instituições Comportamentais" ocorre uma redução de 7,03\% na área plantada de soja nas organizações rurais amostradas, mantendo os demais fatores constantes. Desse modo, a importância de instituições informais como tradição, satisfação pessoal, história, 
cultura e valores regionais no desenvolvimento de suas atividades pecuárias reduzem o avanço de soja nas organizações rurais investigadas. Esse resultado vai ao encontro de Viana \& Waquil (2014), ao determinar que as normas de comportamento exercem papel preponderante na manutenção da produção pecuária no Rio Grande do Sul.

Por outro lado, verifica-se que as Instituições Econômicas também influenciam o avanço de soja, com uma relação positiva, comportamento inverso aos coeficientes angulares dos fatores socioambientais e comportamentais. Constata-se que para cada aumento na escala de importância do fator "Instituições Econômicas" ocorre um aumento de $8,90 \%$ na área plantada de soja nas organizações pecuárias pesquisadas, mantendo os demais fatores constantes $(P<0,10)$. Isto é, a proeminência de instituições como a busca pela maximização do lucro, a importância da tecnologia, o acesso aos insumos produtivos e informações sobre o mercado influenciam positivamente o avanço de áreas de soja dentro de organizações pecuárias. Já o fator de Instituições Organizacionais não demonstrou significância estatística no modelo estimado.

Portanto, a partir dos resultados significativos obtidos no modelo Tobit, verifica-se que os pecuaristas da região da Campanha com um maior grau de presença de instituições socioambientais e comportamentais no seu processo de escolha e decisão apresentam menos chances de inserir a sojicultura em suas organizações agropecuárias. Ao passo que os pecuaristas que demonstram maior envolvimento com as Instituições Econômicas apresentam maiores chances de inserir a atividade de sojicultura em sua organização rural. A influência positiva de questões econômicas no avanço de soja, identificada no modelo institucional da região da Campanha, corrobora as afirmações apresentadas no estudo de Anholeto \& Massuquetti (2015), de que a expansão de lavouras de soja em regiões tradicionalmente reconhecidas pela atividade pecuária ocorreu devido a incentivos financeiros, abertura dos mercados internacionais, tecnologia e, sobretudo, por mostrar-se como uma alternativa mais rentável das atividades agropecuárias. Além disso, a influência de instituições econômicas nas decisões tomadas pelos pecuaristas que inseriram a sojicultura em suas atividades torna-se um importante fator explicativo das transformações ocorridas na região do Pampa, pois além de representarem uma reestruturação das atividades, gerando novos impulsos de investimento e o avanço da atividade na região, refletem uma intenção e estímulo pessoal dos pecuaristas.

Pode-se dizer que o fortalecimento das instituições econômicas transformou o ambiente produtivo e o perfil dos pecuaristas da região, modificando os hábitos de pensamento e construindo novas interpretações e modos de agir. Dessa forma, é possível verificar que a decisão dos pecuaristas em inserir o cultivo de soja em suas organizações, além de revelar uma reestruturação do espaço agrário e diversificação das atividades produtivas, indica um processo de mudança institucional projetando um novo cenário na pecuária de corte.

Ao analisar a influência negativa das Instituições Socioambientais no avanço da soja na Campanha Gaúcha, pode-se constatar que os dados confirmam os resultados obtidos no estudo de Nicola (2015), que identificou que, entre pecuaristas da região, o plantio de lavouras de soja não é considerado uma alternativa viável, pois é visto como uma atividade que modifica a paisagem dos campos naturais, diminui a produtividade e prejudica a preservação do Bioma Pampa. Nesse sentido, as Instituições Socioambientais identificadas neste estudo podem ser caracterizadas como instituições enraizadas em hábitos, costumes, valores comuns que fundamentam as decisões em determinada sociedade (North, 1991). A preocupação com a preservação do ambiente, a sustentabilidade, a cooperação com produtores e a responsabilidade social da empresa remetem a ações que possibilitam o envolvimento dos pecuaristas com organizações de apoio, e a formação de ações coletivas abarcam desde costumes individuais a interesses sociais que formam os padrões de conduta do grupo (Commons, 1931). Dessa forma, são essas instituições informais que restringem os interesses individuais dos pecuaristas ao inserir o cultivo de soja nas organizações rurais.

Assim, estas instituições são responsáveis por determinar o comportamento dos indivíduos e o desempenho econômico do setor. Conforme abordado por North (1994), as instituições informais são regras e normas que se originam das crenças dos seres humanos. 
Isto é, as crenças que os indivíduos incorporam nas sociedades determinam suas escolhas e são consequências de um aprendizado que se acumula ao longo do tempo transmitido culturalmente por toda a sociedade. Essa relação, entre crenças e instituições, se apresenta como convenções e códigos de conduta profundos, pois incorporam as características culturais e os códigos morais de uma sociedade.

Portanto, verifica-se que as instituições presentes na nova dinâmica da pecuária de corte da Campanha Gaúcha são as Instituições Econômicas, estas relacionadas ao avanço da soja na metade sul do Rio Grande do Sul, e as Instituições Socioambientais e Comportamentais, que restringem o avanço da soja na região. Desse modo, compreender a nova dinâmica estabelecida na pecuária de corte da Campanha Gaúcha significa reconhecer o indivíduo como determinante da escolha de suas atividades produtivas, influenciado pelas suas motivações, hábitos de pensamento, ações coletivas e trajetória histórica. Reforçando a importância da utilização da abordagem Institucional, assim como das instituições (formais e informais), não apenas como componentes de análise, mas como agente principal nas transformações ocorridas nas organizações e no meio rural.

\section{Conclusões}

A pesquisa possibilitou explorar fenômenos empíricos com base na teoria institucional, abrindo espaço para novos estudos voltados às organizações rurais. Levando em consideração o arcabouço teórico institucional e a diversidade de instituições presentes na atividade pecuária do Pampa Gaúcho, determinou-se por meio da Análise Fatorial Exploratória (EFA) quatro fatores institucionais: Instituições Econômicas, Instituições Organizacionais, Instituições Comportamentais e Instituições Socioambientais. De tal modo, a construção desses fatores possibilitou agrupar dezessete (17) variáveis institucionais pelas suas semelhanças, facilitando a análise dos dados da pesquisa. Como contribuição do estudo, entende-se possível a replicação desses mesmos constructos em outras realidades rurais, a fim de analisar a dinâmica institucional de distintos setores agroindustriais.

Considerando os fatores institucionais encontrados, e por meio de uma análise comparativa, constatou-se ainda que os Pecuaristas Tradicionais têm como principais motivações para atuar na bovinocultura de corte aspectos como a satisfação e a tradição, valorizando os processos históricos, ambientais e culturais nas suas atividades produtivas. Tendo maior aproximação, portanto, com os fatores Instituições Comportamentais $e$ Instituições Socioambientais. Já os Pecuaristas Sojicultores, por sua vez, obtiveram médias superiores em variáveis dos fatores de Instituições Econômicas e Instituições Organizacionais, demonstrando maior aproximação com as instituições relacionadas ao lucro e a coordenação das atividades agropecuárias. Os resultados corroboram a existência de diferenças entre instituições de pecuaristas tradicionais e pecuaristas sojicultores, que incluem elementos como motivações pessoais e características de natureza organizacional e econômica, demonstrando a heterogeneidade de hábitos de pensamentos na nova dinâmica da pecuária de corte da Campanha Gaúcha.

Ao estimar o modelo Tobit múltiplo, verificou-se a influência das variáveis independentes (fatores institucionais) sobre a variável dependente (\% área plantada de soja) nas organizações rurais amostradas. Evidenciando-se, portanto, a existência de uma relação de dependência entre Instituições Socioambientais, Econômicas e Comportamentais e o percentual de cultivo de soja nas organizações pecuárias amostradas. Diante desses resultados, foi possível verificar que a heterogeneidade de hábitos de pensamentos dos pecuaristas influenciou o avanço do cultivo da soja na região da Campanha Gaúcha, sendo impulsionado por pecuaristas que apresentam instituições comportamentais e socioambientais mais frágeis.

Assim, os resultados da pesquisa demonstraram que os pecuaristas não são influenciados apenas por motivações de ordem econômica e produtiva, mas são determinados também por motivações de ordem não econômica, ou seja, por hábitos e padrões de conduta que moldam as decisões dos indivíduos, reprimindo a substituição de atividades induzidas pelo mercado e políticas de crédito. Levando em consideração essa importância das instituições não econômicas, torna-se imperioso refletir sobre a 
necessidade de uma política pública específica para o Bioma Pampa brasileiro, que estimule a conservação dos campos naturais e a biodiversidade do bioma, reconhecendo os serviços ecossistêmicos gerados pela exploração pecuária.

Portanto, os resultados apresentados em torno dos hábitos de pensamento e comportamento dos Pecuaristas Tradicionais e Sojicultores da região da Campanha Gaúcha possibilitam a exploração de fenômenos empíricos com base na Teoria Institucional, abrindo espaço para novos estudos voltados para o entendimento de outras atividades agrícolas. Destaca-se, portanto, como sugestões para pesquisas futuras a investigação das instituições presentes em diferentes atividades agropecuárias, comparando regiões e sistemas de produção, com o objetivo de comprovar a existência de instituições que norteiam os comportamentos dos indivíduos, baseado em hábitos, costumes e motivações. E assim fortalecer a perspectiva institucional nos estudos sobre as organizações rurais.

\section{Referências}

Agne, C. L. (2014). Mudanças institucionais na agricultura familiar: as políticas locais e as políticas públicas nas trajetórias das famílias nas atividades de processamento de alimentos no Rio Grande do Sul (260p.) (Tese de doutorado) - Universidade Federal do Rio Grande do Sul, Porto Alegre.

Anholeto, C. D., \& Massuquetti, A. (2015). A soja brasileira e gaúcha no período 1994-2010: uma análise da produção, exportação, renda e emprego. Revista Economia e Desenvolvimento, 13(2), 379-404.

Coase, R. H. (1937). The nature of the firm. Economica, 4(16), 386-405.

Coase, R. H. (1998). The New Institution Economics. The American Economic Review, 88(2), 72-74.

Conceição, O. A. C. (2016). A dimensão institucional do processo de crescimento econômico: inovações e mudanças institucionais, rotinas e tecnologia social. Economia e Sociedade, 17(1), 85-108.

Commons, J. R. (1931). Institutional economics. The American Economic Review, 21, 648-657.

Dugger, W. (1990). The New Institutionalism: new but not Institutionalist. Journal of Economic Issues, 24(2), 423-431.

Fundação de Economia e Estatística - FEE. (2016). Painel do agronegócio. Porto Alegre: FEE.

Glasenapp, S. (2016). As instituições na trajetória das transformações produtivas e organizacionais das famílias produtoras de tabaco no Rio Grande do Sul (RS) (253 p.) (Tese de Doutorado). Universidade Federal do Rio Grande do Sul, Porto Alegre.

Gujarati, D. (2006). Econometria básica. Rio de Janeiro: Elsevier.

Hair, J. F., Anderson, R. E., Tatham, R. L., \& Black, W. C. (2009). Análise multivariada de dados. Porto Alegre: Bookman.

High, C., Pelling, M., \& Nemes, G. (2005). Understanding informal institutions: networks and communities in rural development. London: Kings College London.

Hodgson, G. M. (1998). On the evolution of Thorstein Veblen's evolutionary economics. Cambridge Journal of Economics, 22, 415-431.

Hodgson, G. M. (2000). What is the essence of institutional economics? Journal of Economic Issues, 34(2), 317-329.

Instituto Brasileiro de Geografia e Estatística - IBGE. (2019). Pesquisa Agrícola Municipal. Recuperado em 3 de novembro de 2019, from http://www.sidra.ibge.gov.br

Kherallah, M., \& Kirsten, J. (2010). The new institutional economics: applications for agricultural policy research in developing countries (MSSD Discussion Paper 41). Washington, DC: IFPRI.

Kuplich, T. M., Capoane, V., \& Costa, L. F. F. (2018). O avanço da soja no Bioma Pampa. Boletim Geográfico do Rio Grande do Sul, 31, 83-100.

Mcdonald, J. F., \& Moffitt, R. A. (1980). The uses of Tobit analysis. The Review of Economics and Statistics, 62(2), 318-321.

Mitchell, W. (1910). The rationality of economic activity: II. Journal of Political Economy, 18(3), 197-216.

Nicola, M. P. (2015). Espaço protegido e desenvolvimento rural: práticas e trajetórias na pecuária familiar da região Centro Sul do Rio Grande do Sul (Tese Doutorado). Universidade Federal do Rio Grande do Sul, Porto Alegre.

North, D. C. (1994). Economic performance through time. The American Economic Review, 84(3), 359-368. 
North, D. C. (1990). Institutions, institutional change and economic performance. Cambridge: Cambridge University Press.

North, D. C. (1991). Institutions. The Journal of Economic Perspectives, Nashville, 5(1), 97-112.

Oliveira, L. F. T., \& Silva, S. P. (2012). Mudanças institucionais e produção familiar na cadeia produtiva do leite no Oeste Catarinense. Revista de Economia e Sociologia Rural, 50(4), 705-720.

Oliveira, U., Soares-Filho, B. S., Paglia, A. P., Brescovit, A. D., De Carvalho, C. J., Silva, D. P., \& Stehmann, J. R. (2017). Biodiversity conservation gaps in the Brazilian protected areas. Scientific Reports, 7(1), 1-9.

Olsen, W., \& Morgan, J. (2010). Institutional change from within the informal sector in Indian rural labour relations. International Review of Sociology, 20(3), 535-555.

Rutherford, M. (2001). Institutional economics: then and now. The Journal of Economic Perspectives, 15(3), 173-194.

Rutherford, M. (1998). Veblen's Evolutionary Programme: a promise unfulfilled. Cambridge Journal of Economics, 22, 463-477.

Samuels, W. (1995). The presente state of institutional economics. Cambridge Journal of Economics, 19, 569-590.

Silveira, V. C. P., González, J. A., \& Fonseca, E. L. (2017). Land use changes after the period commodities rising price in the Rio Grande do Sul State, Brasil. Ciência Rural, 47(4)

Silva, P. X., \& Cario, S. A. (2016). Para além da interpretação do papel da agricultura no desenvolvimento econômico brasileiro: uma leitura sob perspectiva evolucionária-institucionalista. Desenvolvimento Socioeconômico em Debate, 2(1), 39-63.

Stevenson, W. J. (2001). Estatística aplicada à Administração. São Paulo: Harper \& Row do Brasil.

Veblen, T. (1987). A teoria da classe ociosa. São Paulo: Nova Cultural.

Veblen, T. (1898). Why is economics not an evolutionary science? The Quarterly Journal of Economics, 12(4), 373-397.

Viana, J. G. A., \& Waquil, P. D. (2014). Uma perspectiva evolucionária da economia agrícola: o caso da produção ovina no Brasil e Uruguai. Revista de Economia e Sociologia Rural, 52(3), 471-494.

Williamson, O. E. (1985). The Economic Institutions of Capitalism. The Free Press, New York.

Williamson, O. E. (2000). The New Institutional Economics: taking stock, looking ahead. Journal of Economic Literature, 38, 595-613.

Submetido: 4/Out./2018.

Aceito: 3/Nov./2019

Classificação JEL: B52, Q13 